\title{
Malign özofagus darlığı olgusunda multipl stent uygulaması
}

\author{
Treatment of malignant esophageal obstruction with multiple esophageal stents
}

Mustafa YAKUT, Kubilay ÇINAR, Ramazan IDILMAN, Kadir BAHAR

Ankara Üniversitesi Tıp Fakültesi Gastroenteroloji Bilim Dalı, Ankara

Özofageal stentler en sık olarak, cerrahinin uygun olmadığı özofagus kanserli hastalarda, malign disfajinin palyasyonunda kullanılmaktadır. Inoperabl özofagus kanseri tanısı 24 aydır takip edilen 77 yașındaki erkek hastada gastroskopide özofagusta 20. cm'de lümeni tam daraltan malign darlık izlendi. Hastaya daha önce multipl metal stent uygulaması yapılmıştı. Endoskopik olarak floroskopi yardımı ile beşinci kez metal stent yerleştirildi.

Anahtar kelimeler: Özofagus metal stent, multipl, özofagus kanseri
The most common indication for placement of an esophageal self-expanding metal stent is palliation of malignant dysphagia in patients with tumors of the esophagus. We present a 77-year-old female with a 24-month history of inoperable cancer of the esophagus. Esophagogastroduodenoscopy was performed, which revealed a large ulcerated and obstructing mass in the $20^{\text {th }}$ centimeter of the esophagus. Multiple esophageal stents were placed. A fifth selfexpanding metal endoprosthesis was placed under endoscopic guidance with the aid of fluoroscopy.

Key words: Esophageal metal stents, multiple, esophagus cancer

pak verilerek lümenin açık olduğu doğrulandı. 2 yıl içerisinde tümörün proksimale invazyonu nedeni ile daha yukarı toplam 5 adet stent yerleştirme ihtiyacı oldu. Görüntüde 5 adet stent seçilebilmektedir (Şekil 2).

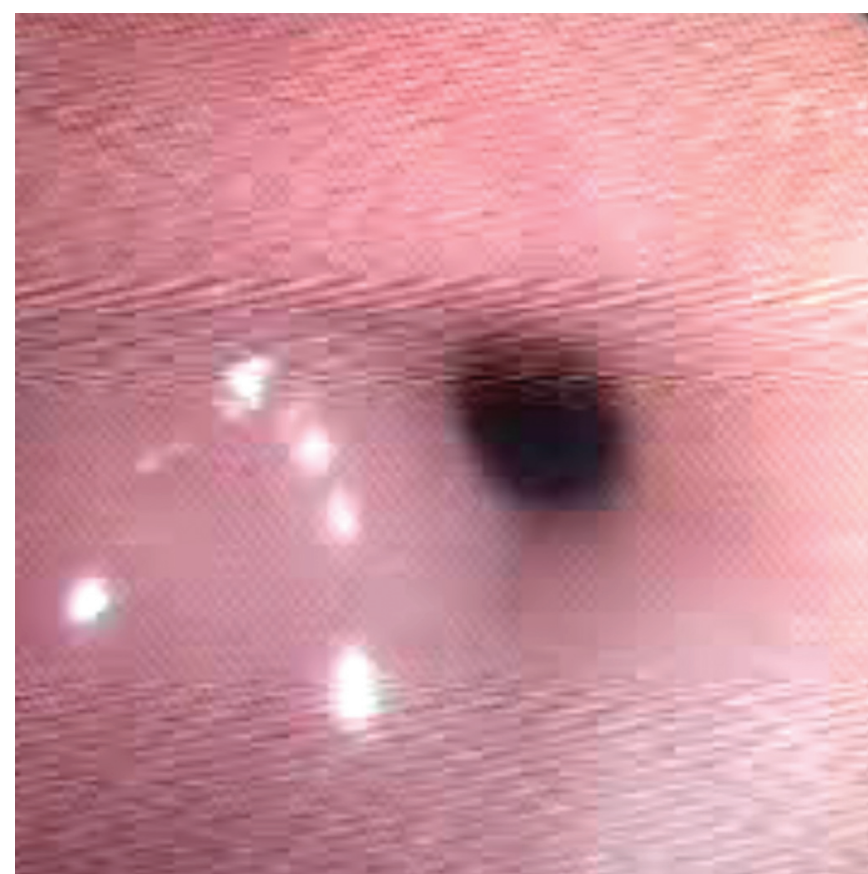

Şekil 1. Endoskopik muayenede özofagus lümeni ileri derecede daralmıs olarak gözleniyor 


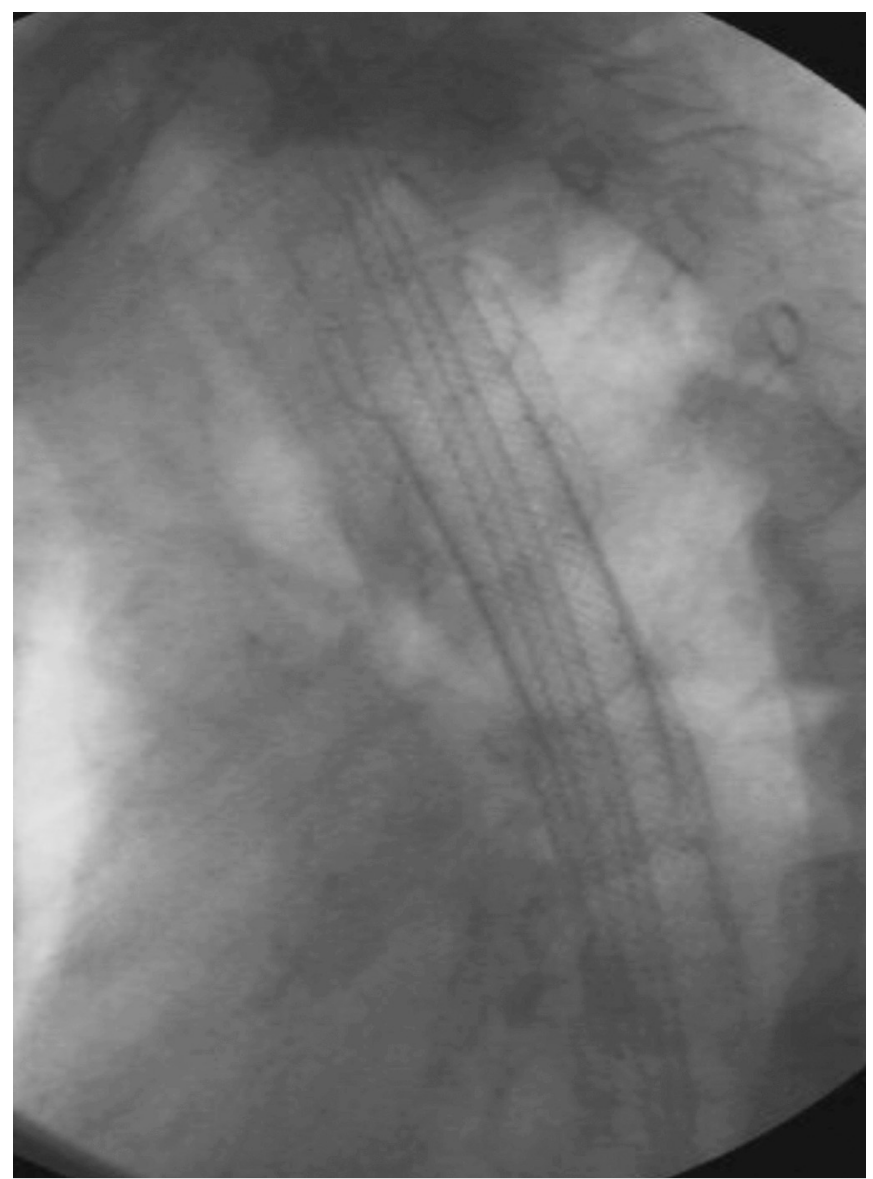

Şekil 2. Floroskopide iç içe açılmış 4 adet stent görünümü

\section{KAYNAKLAR}

1. Slazenger and Fortran's. Gastrointestinal and Liver Disease. Ninth edition. P 745-53.

2. Lambert R. An overview of the management of cancer of the esophagus. Gastrointest Endosc Clin N Am 1998; 8: 415-34

3. Lambert R. Treatment of esophagogastric tumors. Endoscopy 2003; 35: $118-26$

\section{TARTIȘMA}

Özofageal stentler en sık cerrahinin uygun olmadığı özofagus kanserli hastalarda kullanılmaktadır. Ayrıca benign özofageal darlıklarda, özofagus perforasyonunda, benign-malign özofagorespiratuvar fistüllerde de özofagusa stent uygulaması yapılabilir (1-5)

Özofagus kanseri olgularının çoğu tanıda cerrahi sınırları aşmış durumdadır ve küratif cerrahi şansını kaybetmiştir $(1,2)$. Domschke ve arkadaşlarının ilk tanımlamasından sonra bir çok makalede kendi kendine genişleyen stentlerin özofagus kanserli olgularda palyasyondaki etkinliği bildirilmiştir (1-5).

Kendiliğinden genişleyebilen metalik stentler yerleştirilmesine bağlı komplikasyonlar görülebilir. Işlem sırasında sedasyona bağlı komplikasyonlar, aspirasyon, stentin malpozisyonu ve özofagus perforasyonu görülebilir. Erken dönemde gö̆üs ağrısı, kanama, trakea basısı ve solunum sorunları olabilir. Geç dönemde stentin distale migrasyonu, perforasyon ve stent okluzyonu görülebilir.

$\mathrm{Bu}$ olgumuzda özofagus distaline yerleştirilen ilk metal stent uygulaması sonrası zaman içerisinde proksimale doğru tümör yayilması ve stenti daraltması nedeni ile toplam 5 adet stent uygulaması gerekti. En son olarak özofagus üst kısıma doğru 4. metal stentin proksimalini daraltan tümör ekspansiyonu için tümörün proksimalinde olacak şekilde 5. metal stent uygulaması yapildı.

4. Domschke W, Foerster EC, Matek W, Rödi W. Self-expanding mesh stent for esophageal cancer stenosis. Endoscopy 1990; 22: 134-6.

5. Shim CS, Jung IS, Bhandari S, et al. Management of malignant strictures of the cervical esophagus with a newly designed self-expanding metal stent. Endoscopy 2004;36: 554-7. 